\title{
Diffuse cavitary lung lesions: reply to Marchiori et al.
}

\author{
Mindy L. Grunzke • Timothy Garrington
}

Received: 25 January 2010 / Accepted: 25 January 2010 /Published online: 24 February 2010

(C) Springer-Verlag 2010

Sir,

We appreciate the comments of Marchiori et al. [1] and their recommendation for inclusion of benign neoplasm in the differential diagnosis of multiple cavitary lung lesions. Our case illustrates that coming to a correct diagnosis in this situation can be difficult [2]. Considering all diagnostic possibilities, including malignancy, early in the process it is important to allow steps to be taken to make a specific diagnosis and avoid delays in the initiation of the appropriate therapy. In the case we presented, PET/CT played an important role in guiding our choice of location to biopsy to obtain a definitive diagnosis. Earlier use of
PET/CT may have led to a more rapid diagnosis. We agree that PET/CT, while it may provide clues, is not a specific diagnostic test and does not distinguish malignancy from alternative benign conditions.

\section{References}

1. Marchiori E, Zanetti G, Mano CM (2010) Tracheobronchial papillomatosis with diffuse cavitary lung lesions. Pediatr Radiol. doi:10.1007/s00247-010-1573-0

2. Grunzke M, Hayes K, Bourland W et al (2009) Diffuse cavitary lung lesions. Pediatr Radiol 40:215-218

M. L. Grunzke $(\bowtie) \cdot$ T. Garrington

The Rick Wilson Center for Cancer and Blood Disorders,

The Children's Hospital and The University of Colorado at Denver,

13123 E. 16th Ave., B115,

Aurora, CO 80045, USA

e-mail: Grunzke.Mindy@tchden.org 